\title{
REVISÃO SOBRE O PRESÍDIO FEMININO NOS ESTUDOS BRASILEIROS
}

\author{
REVISIÓN SOBRE EL PRESIDIO FEMENINO \\ EN LOS ESTUDIOS BRASILEÑOS \\ REVIEW ON THE FEMALE
RISON IN BRAZILIAN STUDIES
}

\author{
Júlia Sursis Nobre Ferro Bucher-Maluschke', \\ Jonas Carvalho e Silva ${ }^{12}$ e Isabela Brito dos Santos de Souza ${ }^{3}$ \\ ${ }^{1}$ Centro Universitário de Brasília, Brasília/DF, Brasil \\ ${ }^{2}$ German Chancellor Fellow - Fundação Alexander von Humboldt, Alemanha \\ ${ }^{3}$ Universidade Católica de Brasília, Brasília/DF, Brasil
}

\begin{abstract}
RESUMO: O Brasil é o quarto país com a maior população prisional do mundo e o número de mulheres encarceradas vem crescendo rapidamente. Esta revisão narrativa da literatura tem por objetivo identificar as pesquisas das universidades brasileiras sobre o cárcere feminino. Foram analisadas as características e metodologias gerais das 55 investigações incluídas na Biblioteca Digital Brasileira de Teses e Dissertações (BDTD) e os problemas de pesquisa das 17, que obtiveram a classificação A na avaliação dos 10 itens do CASP Checklist, na década de 2006-2016. Os resultados apresentaram a maioria de estudos qualitativos, pesquisados nas regiões centro-sul e com estratégias de intervenção. Esta pesquisa contribuiu para descrever os aspectos da realidade feminina no cárcere e deu subsídios para o processo de ensino e de intervenção daqueles que atuam nessa realidade.
\end{abstract}

PALAVRAS-CHAVE: Prisões; Mulheres; Pesquisa; Revisão.

RESUMEN: Brasil es el cuarto país con la mayor población encarcelada del mundo y el número de mujeres ha crecido rápidamente. Esta revisión narrativa de la literatura tiene por objetivo identificar las investigaciones de las universidades brasileñas. Se analizaron las características y metodologías generales de las 55 investigaciones incluidas en la Biblioteca Digital Brasileña de Tesis y Disertaciones (BDTD) y los problemas de investigación de las 17 que obtuvieron la clasificación A en la evaluación de los 10 ítems del CASP Checklist, en la década de 2006-2016. Los resultados presentaron la mayoría de estudios cualitativos, investigados en las regiones centro-sur y con estrategias de intervención. Esta investigación contribuyó a describir los aspectos de la realidad femenina en la cárcel y dio subsidios para el proceso de enseñanza y de intervención de aquellos que actúan en esa realidad.

PALABRAS-CLAVE: Prisiones; Las mujeres; La investigación; Revisión.

ABSTRACT: Brazil is the fourth country with the largest prison population in the world and the number of incarcerated women has been growing rapidly. This narrative review of the literature aims to identify the research of Brazilian universities. We analyzed the characteristics and the general methodologies of 55 studies included in the Brazilian Digital Library of Theses and Dissertations (BDTD) and the research problems of the 17 that obtained the classification A in the evaluation of the 10 items in CASP Checklist, between the decade of 2006-2016. The results presented the majority of qualitative studies, researched in the center-south regions and with intervention strategies. This research contributed to describe the aspects of the female reality in the prison and gave subsidies for the teaching process and intervention of those who act in that reality.

KEYWORDS: Prison; Women; Research; Review. 


\section{Introdução}

Os dados fornecidos pelo Departamento Penitenciário Brasileiro (INFOPENDEPEN) constatam que o Brasil é o quarto país com a maior população prisional do mundo, com 707 mil detentos, e a sua população atual é $311 \%$ vezes maior do que a da década de 2000. O déficit carcerário está em torno de 368 mil; uma média de 80\% desse corresponde às unidades masculinas e $20 \%$ às femininas. Sabe-se que existe no país uma população de quase 42 mil mulheres presas em relação ao total, o que representa 40,6 para cada grupo de 100 mil mulheres no país. Na análise por períodos, identificou-se que, entre os anos de 2000 e 2016, a taxa de aprisionamento feminino cresceu $656 \%$, enquanto a masculina cresceu 293\% (Ministério da Justiça, 2018).

Para conhecer a relevância dessa temática, deve-se identificar os estudos que estão sendo realizados nas universidades sobre os presídios para as mulheres. Neste artigo, analisaremos as características dos estudos, os problemas de pesquisa e as metodologias aplicadas no estado da arte. Serão apresentadas as características e as metodologias gerais de todas as dissertações e teses incluídas na revisão e os problemas de pesquisa daquelas que obtiveram nota A nos 10 itens do Critical Appraisal Skill Programme (CASP) Checklist para avaliação das pesquisas qualitativas.

No Brasil, a política que organiza o sistema prisional é regida pela Lei de Execução Penal $n^{\circ}$ 7.210, criada a partir do Código de Processo Penal em 1984. Há cinco anos o Instituto de Pesquisa Econômica Aplicada (IPEA) realizou uma ampla avaliação que traçou o perfil do reincidente criminal e avaliou se as prisões cumprem tanto a função punitiva quanto ressocializadora. A equipe avaliou as condições de assistência à saúde, psicológica, social, jurídica, religiosa e material, além da assistência educacional e ao trabalho. A pesquisa indicou a falta de diálogo entre os atores envolvidos e as dificuldades operacionais e de pessoal, como falhas no monitoramento dos regimes semiabertos e aberto, desvalorização e falta de preparo dos agentes penitenciários e profissionais da assistência (IPEA, 2015).

Diante das várias problemáticas referentes ao encarceramento feminino brasileiro, no ano de 2014 o Governo Federal lançou a Política Nacional de Atenção às Mulheres em Situação de Privação de Liberdade e Egressas do Sistema Prisional, a qual se constitui como uma das primeiras iniciativas para a melhoria do encarceramento feminino no país, bem como uma busca em direcionar os Estados da Federação Brasileira na elaboração de políticas estaduais para garantir os direitos humanos para as mulheres em situação de cárcere e egressas do sistema prisional (Portaria n. 210/2014). Nesse contex to, o artigo 37 do Código Penal Brasileiro garante a permanência da mulher presa em uma unidade prisional própria para as mulheres, atendendo a sua condição pessoal (Decreto Lei n. 2848/1940).

Entretanto, pesquisadores relatam que as mulheres passam por diversas negações de direitos, em especial os que deveriam ser mantidos pelo Estado, uma vez que este é responsável por ela até sair do sistema prisional (Cúnico, Brasil, \& Barcinski, 2015; EstevesPereira, Leal, Ayres, Larouzé, \& Sánchez, 2016; Leal et al., 2017; Pereira, 2016; Picoli et al., 2014). O sistema penitenciário brasileiro vem apresentando um formato ineficaz de ressocialização e esse processo ocasiona problemas em escala exponencial de crescimentos. Compreende-se que o crime é um fenômeno complexo que abrange fatores biológicos, ambientais, sociais, econômicos, psicológicos, psiquiátricos, entre outros (Goshin, Arditti, Dallaire, Shlafer, \& Hollihan, 2016; Johnston, 2019). 
Além disso, foi evidenciado no ano de 2007 pelo Relatório sobre mulheres encarceradas no Brasil o histórico de omissão dos poderes públicos e a ausência de quaisquer políticas públicas que considerem a mulher encarcerada como sujeito de direitos inerentes à sua condição de pessoa humana e, muito particularmente, às suas especificidades advindas das questões de gênero segundo o Centro pela Justiça e pelo Direito Internacional (CEJIL, 2007). O relatório aborda ainda as circunstâncias de confinamento das mulheres presas e a responsabilidade do Estado por sua custódia. Demandam-se do poder público as ações ainda mais proativas e um tratamento de fato especializado, com o fim de garantir às mulheres encarceradas o acesso e o gozo dos direitos que lhes são assegurados pela normativa nacional e internacional (Costa, Alves, Fonseca, Costa, \& Fonseca, 2016).

Dada a importância que é a obtenção de estudos referentes à mulher encarcerada, tendo em vista a melhor compreensão desse público, que cresce e se torna alvo de diversas investigações, surgiu o seguinte questionamento: quais são os problemas dos presídios femininos apontados pelos estudiosos nas universidades brasileiras? Visando a sanar tal indagação, pretende-se realizar uma revisão sobre os estudos de Mestrados e Doutorados sobre o cárcere feminino e identificar quais são os problemas investigados tanto pela área da psicologia quanto por áreas correlatas.

O período desta revisão, de 2006 a 2016, coincide com a década referente à Revisão Periódica Universal endereçada ao Brasil pela Organização das Nações Unidas (ONU, 2017), com 240 recomendações para a melhoria das políticas públicas. Dentre os temas abordados estavam combater o uso excessivo da força e os homicídios cometidos pela polícia em "legítima defesa" ou durante a "guerra às drogas"; combater a violência em prisões, bem como a superlotação e as más condições dos lugares de detenção e proteger os defensores de direitos humanos.

A pesquisa sobre as mulheres em situação de privação de liberdade encontra-se em desenvolvimento. Devem-se integrar os campos de atuação por meio do mapeamento da literatura científica a respeito das mulheres encarceradas no Brasil. Esta revisão busca contribuir com os estudos futuros que carecem compreender sobre as diversas realidades observadas e descritas para o aprimoramento das políticas públicas voltadas para o cárcere feminino. Portanto, torna-se relevante o levantamento do estado da arte dentro das universidades brasileiras sobre a temática, tendo em vista a densa produção científica dessas instituições de ensino e pesquisas no cenário nacional e internacional.

\section{Método}

Para realização desta revisão foi utilizada a Biblioteca Digital Brasileira de Teses e Dissertações (BDTD), onde foram encontradas as pesquisas publicadas nos últimos dez anos e que se referiam ao tema. Os critérios de inclusão da revisão foram os estudos catalogados e avaliados que: (a) abordaram a Prisão Feminina no Brasil; (b) eram uma tese ou uma dissertação; (c) haviam sido publicados entre 2006 e 2016. Para a identificação dos trabalhos na base de dados foram adotados os descritores "prisão", "prisão gênero" e "prisão feminina”. Foram incluídos os estudos que não continham os descritores empregados em suas palavras-chave, pois se levou em consideração o conteúdo do resumo.

Com o levantamento total dos estudos encontrados, foram excluídos aqueles: (a) que não atenderam ao objetivo geral da revisão, (b) estudos não fornecidos pelo autor 
quando não estivessem disponíveis integralmente na base de dados por meio do contato eletrônico, (c) estudos que utilizaram nos descritores o termo "prisão" para um sentido que não se referia a "presídio" e (d) as publicações duplicadas, que forneciam outro acesso a um mesmo estudo.

A seleção referente a esses critérios foi realizada inicialmente com a leitura dos títulos, e posteriormente foram lidos os resumos para a inclusão na revisão. Os trabalhos selecionados foram colocados em uma tabela de informações, a qual é dividida em itens que forneciam as informações prévias sobre os estudos encontrados. Finalmente, foram identificados os maiores interesses dos pesquisadores e a qualidade dos estudos a respeito do Presídio Feminino no Brasil (Fig. 1).

Figura 1. Fluxo de informações das diferentes fases da revisão
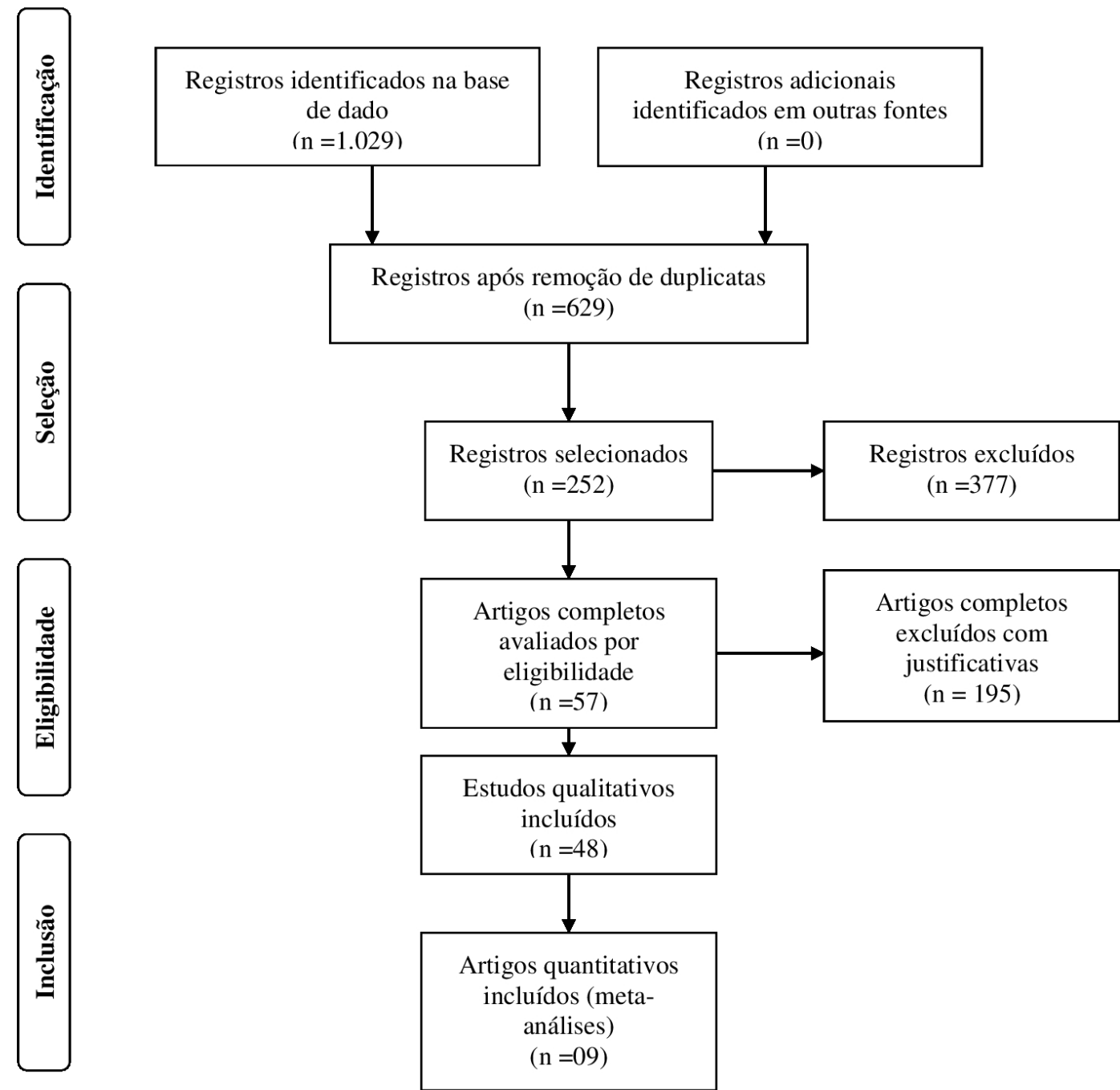

A avaliação metodológica dos estudos utilizou o modelo CASP, instrumento de 10 itens que classifica os estudos qualitativos em duas categorias, conforme a metodologia apresentada pelos estudos. Compondo os critérios estabelecidos estão: (a) objetivo claro e justificado; (b) o desenho metodológico é apropriado aos objetivos; (c) os procedimentos metodológicos são apresentados e discutidos; (d) seleção da amostra intencional; (e) coleta de dados descrita, instrumentos explicitados, processo de saturação; (f) a relação entre pesquisador e pesquisado é considerada; (g) cuidados éticos; (h) análise densa e 
fundamentada; (i) os resultados são apresentados e discutidos, apontam para o aspecto da credibilidade, fazem uso da triangulação; (j) discorrem sobre as contribuições e implicações do conhecimento gerado pela pesquisa, bem como as suas limitações.

A partir da avaliação desses critérios, a qualidade das pesquisas foi categorizada nas classificações $A$ ou $B$. Aquelas que se classificaram na categoria $A$ atenderam a, pelo menos, nove itens dos dez indicados, obtendo a aprovação suprema. Já as de categoria B atenderam até cinco itens dos dez, obtendo a aprovação parcial. Destarte, foram analisadas as características e metodologias gerais das 55 teses e dissertações incluídas na revisão e os problemas de pesquisa das 17 que obtiveram a classificação A na avaliação dos 10 itens do CASP Checklist para as pesquisas qualitativas.

\section{Resultados e discussão}

Na primeira etapa da busca pelos os estudos foram encontrados para o descritor "prisão" 596, divididos em 383 dissertações e 110 teses. Com o descritor "prisão gênero" foram encontrados 55, sendo 41 dissertações e 14 teses. E com o descritor "prisão feminina" foram encontrados 50, sendo 36 dissertações e 14 teses. Com base nos critérios de exclusão foram retirados os que não se encaixavam nos objetivos do presente trabalho.

\section{Caracterização das pesquisas}

Foram analisadas 38 dissertações de mestrado e 19 teses de doutorado produzidas a partir de pesquisas sobre o presídio feminino no Brasil e publicadas entre 2006 e 2015. Conforme apresentado na Figura 2, a ampliação das pesquisas acerca do tema tratado neste estudo nos últimos anos ressalta o elevado número de estudos publicados no ano de 2015.

Figura 2. Número dos estudos desenvolvidos nos últimos 10 anos.

\section{$\underline{\underline{\underline{\underline{\underline{\underline{E}}}}} \text { Teses }} \underline{\underline{\underline{\underline{\underline{\underline{E}}}}} \text { Dissertações }}$}

\section{2}

10

8

6
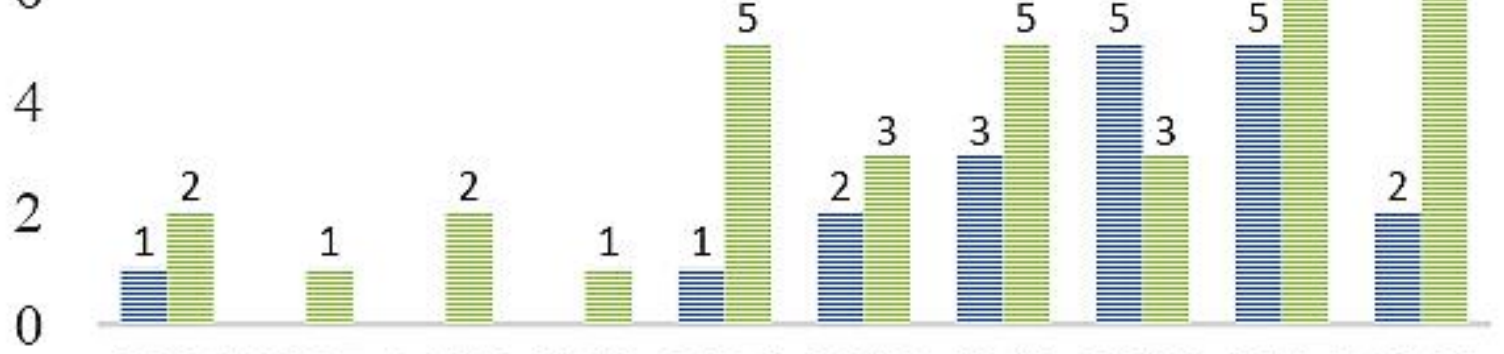

0

10

2006200720082009201020112012201320142015 
Foi observado o alto índice das investigações envolvendo o cárcere, mas, quando se trata daquelas referentes ao presídio feminino, o número regrediu consideravelmente. Somente $17 \%$ dos estudos encontrados tratam da abordagem "prisão gênero" ou "prisão feminina” e apenas $9 \%$ foram incluídas para a presente revisão.

As pesquisas analisadas foram realizadas por 25 instituições de ensino distribuídas entre públicas e privadas. Os estados que tiveram participação foram: Rio Grande do Norte, Rio Grande do Sul, Minas Gerais, Pernambuco, São Paulo, Bahia, Paraíba, Paraná, Maranhão, Sergipe, Goiás, Ceará, Rio de Janeiro e o Distrito Federal. Englobaram-se 14 dos 26 estados existentes no Brasil. Nota-se a maior participação de alguns estados como São Paulo, Rio Grande do Sul e Rio de Janeiro. Também se percebe a carência de outros estados, principalmente os que não tiveram participação na base de que esta pesquisa utilizou como fonte.

A revisão também averiguou as disciplinas que estão à frente no campo prisional observado na Figura 3. Foram identificados os estudos da Psicologia (7) com maior número, subdividido nas áreas da Psicologia (3), Psicologia Social (2) e Psicologia Cognitiva (2). Eles caracterizaram as vivências, subjetividades, os cotidianos, relacionamentos afetivos de detentas e a experiência dos comportamentos violentos dentro dos presídios femininos. Apenas cinco do total das pesquisas foram realizadas por homens.

\section{Figura 3. Áreas de investigação}

\section{ÁREAS DOS ESTUDOS}

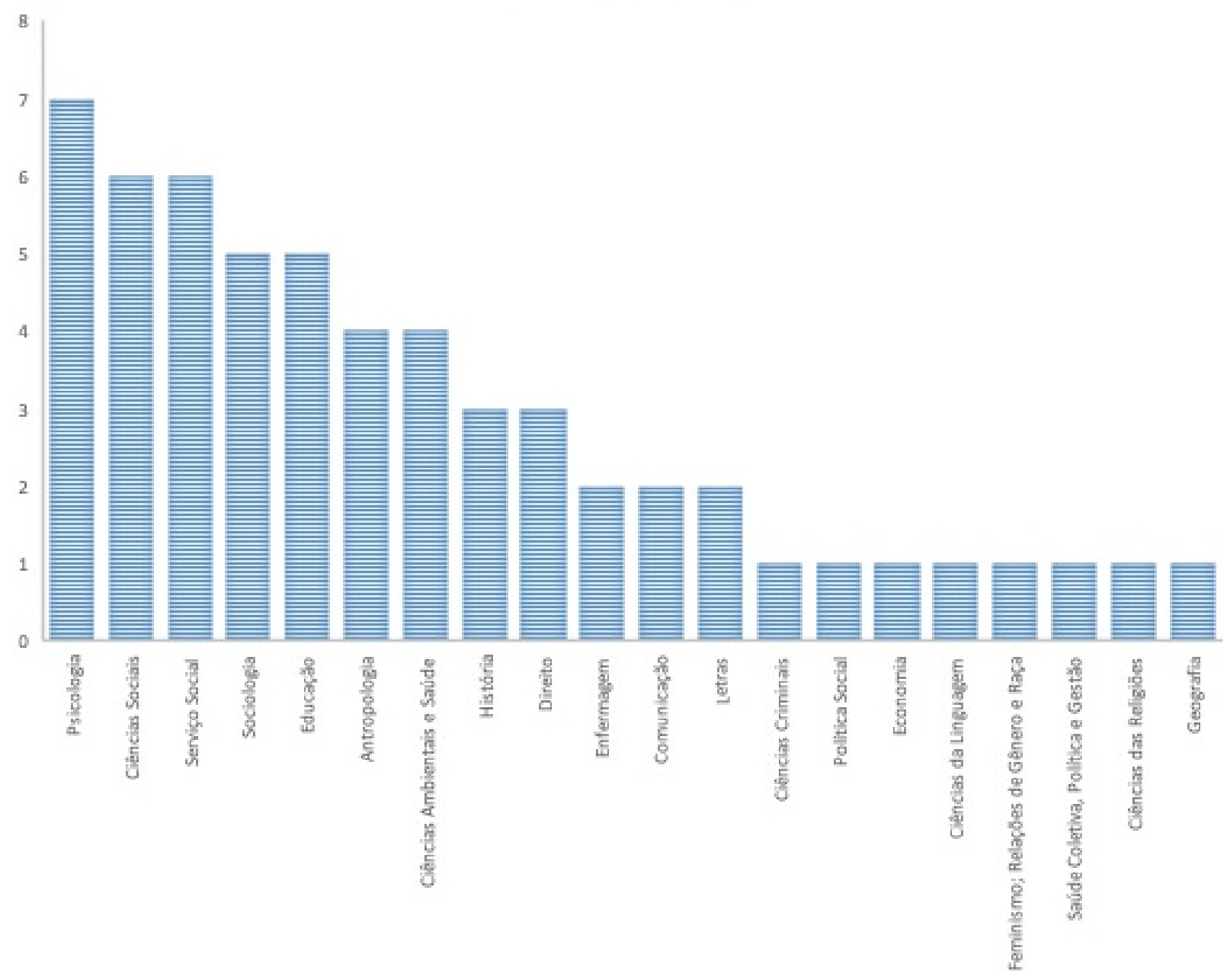


As áreas das Ciências Sociais (6) e Serviço Social (6) estão em destaque também. A primeira apontou a seletividade penal no que se referem às rés negras, os vínculos entre as agentes penitenciárias e as aprisionadas, a ressocialização, o trabalho e a maternidade. O Serviço Social está na área investigando as experiências, transformações, e buscando caracterizar as pessoas que ocupam esse espaço visto de forma preconceituosa por uma parcela significativa da população e das instituições.

A Sociologia (5) está presente nos estudos empíricos no que diz respeito ao tráfico de drogas, maternidade, relações sexuais, questões de identidade pós-cárcere, interações sociais dentro do presídio e religiosidade, ou seja, uma área que contribui com estudos diversificados para o campo prisional. Com o mesmo número da Sociologia está a Educação (5), que investiga as cartas feitas pelas detentas e os seus familiares, o sentido das experiências escolares fora e dentro da prisão, a escrita das detentas e o processo da ressocialização.

A área das Ciências Ambientais e Saúde (4) se destacou na revisão pelo número de pesquisas quantitativas sobre a prevalência dos agravos à saúde nos presídios brasileiros. A Antropologia (4) busca compreender as experiências e a organização das aprisionadas, conectando as vivências dos indivíduos dentro e fora da prisão. Foram destacados os participantes que estão fora do cárcere, relações familiares entre detentos e os relacionamentos afetivos nos presídios de São Paulo em um estudo comparado com os resultados obtidos em amostras de Barcelona /Espanha.

A História (3) está em evidência pelos estudos teóricos sobre os documentos históricos da trajetória dos presídios até os dias de hoje, as mudanças através dos anos e a pesquisa de campo para compreender o cotidiano da mulher ex-detenta. O Direito (3) investigou o trabalho como ferramenta socializadora, o impacto do encarceramento nos filhos das aprisionadas e a proposta de uma nova assistência dos militares com as mulheres.

A Enfermagem (2) estudou os impactos das drogas na vida das mulheres detentas, as atitudes e as práticas das mulheres dentro do presídio. A Comunicação Social (2) investigou o processo de implantação e formação da televisão e da telenovela no Brasil para analisar a fala dos participantes e conhecer o cotidiano das mulheres em situação prisional. Os estudos na área de Letras (2) enfocaram os processos de subjetivação no cárcere feminino por meio das escritas das detentas, problematizando os processos de subjetivação no cárcere.

Entre as mais diversas áreas das ciências estão também as Ciências da Religião (1), que buscou compreender as experiências religiosas. As Ciências Criminais (1) traçaram o perfil de pessoas aprisionadas que cometeram suicídio, estando as mulheres entre os números reduzidos desse fenômeno. As Ciências da Linguagem (1) investigaram a aquisição da segunda língua para as mulheres encarceradas. As Políticas Sociais (1) avaliaram a capacitação de servidoras de penitenciárias femininas. A Economia (1) realizou uma análise documental acerca dos determinantes criminológicos entre períodos específicos.

Os Feminismos, Relações de Gênero e Raça (1) desenvolveram um estudo empírico sobre a heterogeneidade existente nas diversas dinâmicas de aproximação e permanência das mulheres nessa rede criminalizada. A Saúde Coletiva, Política e Gestão em Saúde (1) averiguou as especificidades das detentas e as questões relacionadas à saúde pública. Por fim está a área da Geografia (1) com um estudo teórico, analisando geograficamente a dinâmica da violência criminal no território.

As diversas disciplinas e os objetivos pesquisados apontaram o número significativo dos estudos que analisaram o perfil da população aprisionada, além dos estudos relacionados às mulheres e o envolvimento de drogas. A análise de vivências e experiências 
prisionais também teve aparições relevantes, retratadas em muitos estudos através da escrita. Outros revisores (Barcinski, Cúnico, \& Brasil, 2017; Cúnico et al., 2015) também identificaram em suas análises a perspectiva de gênero e assumiram uma postura crítica a respeito da visão que idealiza a estrutura conservadora da família como construto multidimensional da diversidade cultural e de classe.

\section{Problemas de pesquisa}

A Tabela 1 apresenta os autores, áreas, objetivos e as metodologias dos estudos que obtiveram classificação A no checklist CASP para avaliação das pesquisas qualitativas. Parte dos estudos analisados buscou compreender o início do envolvimento da mulher no contex to criminal (9), englobando também o envolvimento com o tráfico.

Em sua maioria, os resultados foram obtidos através das falas das mulheres (e.g. Moreira, 2012). A proposta de Carneiro (2015) foi identificar as diversas aproximações e a permanência das mulheres na rede da criminalidade, o que inclui o tráfico de drogas. Em segundo plano estão os estudos que abordam a compreensão da vivência da mulher em situação prisional no que tange às hierarquias, divisão do poder, desafios e cotidiano. O estudo de Santos (2013) articulou os processos de subjetivação contemporâneos em relação a hierarquias de gênero e o poder. 
Tabela 1.

\begin{tabular}{|c|c|c|c|}
\hline Autor & Área & Objetivo & Metodologia \\
\hline $\begin{array}{l}\text { (Carneiro, } \\
2015)\end{array}$ & $\begin{array}{l}\text { Ciências da } \\
\text { linguagem }\end{array}$ & $\begin{array}{l}\text { Avaliar o processo de aquisição de } \\
\text { língua inglesa na prisão. }\end{array}$ & Qualitativa \\
\hline $\begin{array}{l}\text { (Gonçalves, } \\
\text { 2015) }\end{array}$ & Comunicação & $\begin{array}{l}\text { Caracterizar mídia televisiva e do } \\
\text { gênero ficcional na formação das } \\
\text { identidades. }\end{array}$ & Documental \\
\hline (Lema, 2015) & Direito & $\begin{array}{l}\text { Compreender como funciona o traba- } \\
\text { lho realizado pelas mulheres presas. }\end{array}$ & \multirow{4}{*}{ Qualitativa } \\
\hline $\begin{array}{l}\text { (Negretti, } \\
2015)\end{array}$ & Ciências sociais & $\begin{array}{l}\text { Compreender a gestão dos vínculos } \\
\text { entre agentes do sistema prisional e } \\
\text { as detentas. }\end{array}$ & \\
\hline $\begin{array}{l}\text { (Padovani, } \\
\text { 2015) }\end{array}$ & Antropologia & $\begin{array}{c}\text { Analisar os relacionamentos } \\
\text { afetivos e sexuais. }\end{array}$ & \\
\hline (Alves, 2015) & Ciências sociais & $\begin{array}{l}\text { Análise de raça e da } \\
\text { colonialidade da justiça. }\end{array}$ & \\
\hline (John, 2014) & $\begin{array}{l}\text { Comunicação e } \\
\text { informação }\end{array}$ & $\begin{array}{c}\text { Conhecer o cotidiano de mulheres } \\
\text { em situação de confinamentos a partir } \\
\text { da mediação da telenovela. }\end{array}$ & Documental \\
\hline (Silva, 2014) & Saúde & $\begin{array}{l}\text { Descrever o perfil dos trabalhadores } \\
\text { de uma penitenciária feminina. }\end{array}$ & Quantitativa \\
\hline (Lima, 2013) & Antropologia & $\begin{array}{c}\text { Articular os pontos de vistas } \\
\text { dos membros sobre a compreensão } \\
\text { de família. }\end{array}$ & \multirow[t]{2}{*}{ Qualitativa } \\
\hline (Sá, 2013) & Direito & $\begin{array}{l}\text { Propor uma intervenção policial } \\
\text { alternativa ao que se considera a } \\
\text { transgressão do feminino. }\end{array}$ & \\
\hline (Santos, 2013) & Psicologia & $\begin{array}{c}\text { Articular os processos de } \\
\text { subjetivação, as relações de poder } \\
\text { e as tecnologias em uma Penitenciária. }\end{array}$ & Documental \\
\hline $\begin{array}{l}\text { (Santana, } \\
\text { 2013) }\end{array}$ & Sociologia & $\begin{array}{l}\text { Analisar a religiosidade } \\
\text { evangélica no presídio. }\end{array}$ & Qualitativa \\
\hline $\begin{array}{l}\text { (Moreira, } \\
\text { 2012) }\end{array}$ & Enfermagem & $\begin{array}{l}\text { Identificar os impactos na vida } \\
\text { das mulheres envolvidas no } \\
\text { fenômeno das drogas. }\end{array}$ & Mista \\
\hline $\begin{array}{l}\text { (Oliveira, } \\
2012)\end{array}$ & $\begin{array}{l}\text { Ciências da } \\
\text { Religião }\end{array}$ & $\begin{array}{l}\text { Analisar o campo religioso } \\
\text { prisional feminino. }\end{array}$ & \multirow{4}{*}{ Qualitativa } \\
\hline $\begin{array}{l}\text { (Modesti, } \\
\text { 2011) }\end{array}$ & Direito & $\begin{array}{l}\text { Estudar as consequências } \\
\text { na vida dos filhos. }\end{array}$ & \\
\hline $\begin{array}{l}\text { (Copque, } \\
2010)\end{array}$ & Ciências sociais & $\begin{array}{c}\text { Investigar as representações } \\
\text { sobre a gravidez e a maternidade. }\end{array}$ & \\
\hline $\begin{array}{l}\text { (Padovani, } \\
\text { 2010) }\end{array}$ & Sociologia & $\begin{array}{c}\text { Estudar a relação entre os comporta- } \\
\text { mentos sexuais e a criminalidade. }\end{array}$ & \\
\hline
\end{tabular}




\section{Artigos analisados após avaliação dos itens CASP}

Os trabalhos sobre a ressocialização trataram a inserção da mulher no mercado de trabalho, exercendo alguma atividade laboral dentro dos presídios, como no estudo de Lema (2015). Foram investigados também os agentes penitenciários, os profissionais da saúde e os policiais para compreender os vínculos deles com as detentas, bem como identificar as novas práticas de relacionamento, como apontam os estudos de Negretti (2015) e de Sá (2013).

As pesquisas com famílias estão sendo realizadas na busca de compreender como é visto o encarceramento de uma mulher para esse público com destaque para a percepção das cunhadas, retratada por Lima (2013), dos filhos (Modesti, 2011), e da família extensa (Silva, 2014), que identificaram as transformações ocorridas em uma família a partir do encarceramento de sua responsável. Os estudos sobre raça, gênero e representatividade da história de vida das mulheres internalizadas, acerca da diferenciação do que é feito em julgamento (e.g. Alves, 2015), apontaram a seletividade penal para as mulheres negras.

Houve também os estudos que abordaram o comportamento sexual das aprisionadas, que era considerado ilegítimo dentro das prisões nos últimos 30 anos, tema abordado por Padovani (2010). Para a sua tese, a mesma autora (Padovani, 2015) trouxe também o interesse nos estudos dos comportamentos sexuais, realizando uma análise dos relacionamentos afetivos nas penitenciárias de São Paulo e Barcelona. No que tange à religiosidade, Santana (2013) estudou a interferência da abordagem evangélica no ambiente carcerário e o número de conversão que existe na prisão. Oliveira (2012) caracterizou a religiosidade de todas as aprisionadas, incluindo também as participantes não religiosas.

As mídias também foram atreladas aos estudos realizados neste levantamento. Gonçalves (2015) apontou a importância da telenovela, especificamente "Insensato Coração", na formação das identidades das presas. John (2014) propôs a utilização das telenovelas como ferramenta de mediação social no contexto prisional. Os pesquisadores da área corroboram que os dados obtidos na linguagem cênica, por meio dos personagens e situações, possibilitam a produção de linhas de fugas e permitem a presa sair de si mesma para o encontro com o estrangeiro e com o diferente (Soares, Félix-Silva, \& Figueiró, 2014).

Houve outros problemas de pesquisa identificados na revisão, mas com baixo número de dissertações e teses que abordaram os processos históricos de transformação das condições do encarceramento das mulheres, tendo em vista a participação no tráfico de drogas; a investigação das mulheres que estão ligadas ao ambiente prisional devido ao envolvimento afetivo com os seus companheiros; análise das cartas das detentas; a gravidez e a maternidade dentro do presídio (Copque, 2010); o cumprimento da pena em regime semiaberto para as mulheres; os projetos futuros das apenadas após o cárcere e, por último, a análise geográfica de um determinado presídio feminino.

\section{Metodologias das pesquisas}

Esta pesquisa realizou a análise dos métodos dos estudos levantados, que foram primeiramente classificados entre teóricos ou empíricos. Em seguida, foram analisados dentro de cada classificação a abordagem da pesquisa, referindo-se à utilização de estudos: qualitativos descritivos, exploratórios, análise documental, análise documental e entrevistas, análise do discurso, misto e quantitativo transversal. Observou-se o elevado índice de pesquisas empíricas, sendo 49 pesquisas em um total de 57. 
Destacaram-se os estudos qualitativos descritivos (24) e estudos qualitativos exploratórios (14), além de três pesquisas com a utilização da análise do discurso. Houve também seis estudos quantitativos transversais, com o intuito de traçar os perfis. A abordagem mista teve um número relativamente pequeno, sendo apenas duas pesquisas. As entrevistas de investigação e as entrevistas semiestruturadas foram os instrumentos mais utilizados ao público-alvo de cada estudo, portanto houve uma verídica pesquisa de campo. Esses dados corroboram a revisão sistemática sobre a maternidade no contex to do cárcere elaborada por Cúnico et al. (2015), que apontou a mesma predominância.

Os seis estudos teóricos identificados analisaram os conteúdos de documentos públicos e históricos. Somente um estudo apresentou a discussão dos resultados e outro incluiu a análise dos documentos públicos e das entrevistas semiestruturadas. A análise do discurso de Bardin (2011) foi a abordagem de três pesquisas por meio da investigação de cartas e do letramento. E, finalizando o número das abordagens de estudos encontrados nessa pesquisa, estão os quantitativos transversais, que compreendem seis estudos que utilizam escalas e questões estruturadas para alinhamento de perfís.

A interação dos problemas de pesquisa estudada influencia na vida das mulheres encarceradas, incluindo o comportamento individual, as famílias, vizinhança, comunidade, cultura e as instalações prisionais. Os problemas individuais consistem no conhecimento, atitudes, crenças, valores e instrução escolar. As mulheres presas geralmente têm educação limitada, o que pode ser relacionado às dificuldades da compreensão positiva sobre si. $\mathrm{O}$ uso abusivo e a atividade criminal relacionada às drogas, tal como a distribuição, foram comumente relacionados às penas dos participantes das pesquisas. Os dados sociodemográficos dos estudos revelam a complexidade dos problemas das pesquisas baseada nas condições econômicas, de raça e gênero.

Os problemas interpessoais foram definidos como os relacionamentos entre os indivíduos com outras pessoas, membros familiares, filhos, amigos, irmãos e as agentes penitenciárias. Essas relações podem gerar influência positiva ou negativa na saúde e no comportamento do indivíduo (França, 2013). Os problemas institucionais das pesquisas envolveram as disparidades entre a legislação e a assistência também baseadas na renda, gênero e raça. Nesse sentido, o referencial teórico dos estudos buscou levantar os documentos oficiais da justiça criminal que envolve as mulheres, as instalações (celas, presídios, creche etc.) e as condições vivenciadas nessas estruturas.

No que tange aos problemas comunitários, as pesquisas examinaram os grupos aos quais as mulheres pertencem, como a família, a vizinhança, as companheiras das celas e os relacionamentos entre elas, os profissionais e a rede de apoio para o tratamento do uso de substâncias e da saúde mental, hospitais, clínicas e outras instalações. Finalmente, as pesquisas também examinaram os fatores políticos, tais como as leis, as políticas públicas e a atenção, que podem comprometer as atitudes e os vínculos emocionais e/ou limitar o acesso das presas à informação e aos recursos.

\section{Considerações}

O objetivo desta pesquisa foi identificar as características dos estudos, os problemas de pesquisa e as metodologias aplicadas no estado da arte. A carência de informação sobre o que está sendo realizado nas dissertações e nas teses das universidades em relação 
à temática proposta neste estudo demandou a necessidade de sistematizar e caracterizar os interesses acadêmicos relacionados à prisão no Brasil. Os resultados obtidos poderão auxiliar as disciplinas de formação dos futuros profissionais e pesquisadores sobre os problemas de pesquisa facilitadores da organização de estratégias de intervenção.

As características e as metodologias gerais incluídas na revisão apontaram a preocupação com o tema abordado. Observou-se o maior número de pesquisas nas universidades das regiões centro-oeste e sul, o que sugere um melhor aparato para o desenvolvimento das pesquisas nesse contexto, preservando a qualidade e a segurança dos pesquisadores. As tragédias ocorridas nas prisões, com um grande número de mortes violentas (Carandiru/ SP, Pedrinhas/MA, Penitenciária de Alcaçus/RN, Anísio Jobim/AM, Monte Cristo/RR, Bem Fica/RJ), levam à necessidade de os pesquisadores direcionarem os seus estudos para uma realidade complexa e interdisciplinar.

Esta pesquisa contribuiu para descrever aspectos da realidade feminina no cárcere e deu subsídios para o processo de ensino e de intervenção daqueles que atuam nessa realidade. Estudos futuros poderão aprofundar a utilização das ferramentas e dos instrumentos de pesquisa e a sua aplicação na realidade prisional. Outros estudos poderão aproximar os resultados das pesquisas nas universidades com legislações nacionais e internacionais e delinear um marco teórico-conceitual com a perspectiva interdisciplinar.

\section{Referências}

Alves, E. A. (2015). Rés negras, judiciário branco: uma análise da interseccionalidade de gênero, raça e classe na produção da punição em uma prisão paulistana. Dissertação de Mestrado, Programa de Pós-graduação em Ciências Sociais, Universidade de São Paulo, São Paulo/SP.

Barcinski, M., Cúnico, S. D., \& Brasil, M. V. (2017). The Meanings of Re-Socialization to Correctional Officers in a Women's Prison: Between Care and Control. Temas Em Psicologia, 25(3), 1271-1283. https://doi.org/10.9788/TP2017.3-16En

Bardin, L. (2011). Análise de Conteúdo. São Paulo: Edições 70.

PORTARIA n. 210, de 16 de janeiro de 2014. (2014). Institui a Política Nacional de Atenção às Mulheres em Situação de Privação de Liberdade e Egressas do Sistema Prisional, e dá outras providências. Recuperado de http://www.lex.com.br/legis 25232895 PORTARIA INTERMINISTERIAL N 210 DE 16 DE JANEIRO DE 2014.aspx

Carneiro, L. G. S. (2015). Mulas, olheiras, chegas $\Xi$ outros tipos: heterogeneidade nas dinâmicas de inserção e permanência de mulheres no tráfico de drogas em Brasília-DF e na cidade do México. Tese de Doutorado, Programa de Pós-graduação em Sociologia,Universidade de Brasília, Brasília, DF.

CEJIL. (2007). Relatório sobre mulheres encarceradas no Brasil. Brasilia. Recuperado de https:// carceraria.org.br/wp-content/uploads/2013/02/Relato\%CC\%81rio-para-OEA-sobreMulheres-Encarceradas-no-Brasil-2007.pdf

Copque, B. A. S. (2010). Uma etnografia visual da maternidade da penintenciária Latavera Bruce. Tese de Doutorado, Programa de Pós-graduação em Ciências Sociais, Universidade do Estado do Rio de Janeiro, Rio de Janeiro/RJ. 
Costa, L. H. R., Alves, J. P., Fonseca, C. E. P., Costa, F. M. , \& Fonseca, F. F. (2016). Género en el marco de los derechos sexuales y reproductivos de las mujeres privadas de libertad. Enfermería Global, 15(3), 138-175. Recuperado de http://revistas.um.es/eglobal/article/ view/207141/194651

Cúnico, S. D., Brasil, M. V., \& Barcinski, M. (2015). A maternidade no contexto do cárcere: uma revisão sistemática. Estud. Pesqui. Psicol., 15(2), 509-528. Recuperado de http://www.e-publicacoes.uerj.br/index.php/revispsi/article/view/17656/13053\%oAhttp://pepsic.bvsalud. org/scielo.php?script=sci_arttext\&pid=S1808-42812015000200005\&lng=pt\&nrm $=$ iso

Decreto Lei n. 2848, de 07 de dezembro de 1940. (1940). Recuperado de http://www.planalto.gov.br/ccivil_03/decreto-lei/Del2848compilado.htm

Esteves-Pereira, A. P., Leal, M. C., Ayres, B. V. S., Larouzé, B., \& Sánchez, A. R. (2016). Nascer na prisão: gestação e parto atrás das grades no Brasil. Ciência E̊ Saúde Coletiva, 21(7), 20612070. https://doi.org/10.1590/1413-81232015217.02592016

França, M. H. O. (2013). Prisão, tráfico e maternidade: um estudo sobre mulheres encarceradas. Tese de Doutorado, Programa de Pós-graduação em Sociologia, Universidade Federal da Paraíba, João Pessoa/PB.

Gonçalves, W. C. (2015). A condessa de Monde Cristo: a representação da identidade da mulher presa na telenovela Insensato Coração. Dissertação de Mestrado, Programa de Pós-graduação em Comunicação, Universidade Federal de Juiz de Fora, MG.

Goshin, L. S., Arditti, J. A., Dallaire, D. H., Shlafer, R. J., \& Hollihan, A. (2016). An International Human Rights Perspective on Maternal Criminal Justice Involvement in the United States. Psychology, Public Policy, and Law, 23(1), 53-67. https://doi.org/10.1037/law000010 1

IPEA. (2015). Reincidência Criminal no Brasil. Brasília, DF: Autor. Recuperado de https:// www.ipea.gov.br/portal/images/stories/PDFs/relatoriopesquisa/150611 relatorio reincidencia criminal.pdf

John, V. M. (2014). Mundos possíveis e telenovela: memórias e narrativas melodramáticas de mulheres encarceradas. Tese de Doutorado, Programa de Pós-graduação Comunicação e Informação, Universidade Federal do Rio Grande do Sul, Porto Alegre, RS.

Johnston, H. (2019). Imprisoned mothers in Victorian England, 1853-1900: Motherhood, identity and the convict prison. Criminology \& Criminal Justice, 19(2), 215-231. https:// doi. org/10.1177/1748895818757833

Leal, M. C., Domingues, R. M. S. M., Larouzé, B., Pereira, A. P. E., Sánchez, A. R., \& Ayres, B. (2017). Prevalence of syphilis and HIV infection during pregnancy in incarcerated women and the incidence of congenital syphilis in births in prison in Brazil. Cadernos de Saude Pública, 33(11), 1-15. https://doi.org/10.1590/0102-311x00183616

Lema, V. M. (2015). O trabalho das mulheres no presídio feminino de Florianópolis. Dissertação de Mestrado, Programa de Pós-graduação em Direito, Universidade Federal de Santa Catarina, Florianópolis/SC.

Lima, J. S. F. (2013). Mulher fiel: as famílias das mulheres dos presos relacionados ao primeiro comando da capital. Dissertação de Mestrado, Programa de Pós-graduação em Antropologia, Universidade Federal de São Carlos, SP

Ministério da Justiça. (2018). Levantamento Nacional de Informações Penitenciárias - Infopen Mulheres (Vol. 2). Brasília, DF: Autor. Recuperado de http://depen.gov.br/DEPEN/depen/ sisdepen/infopen-mulheres/infopenmulheres arte 07-03-18.pdf 
Modesti, M. C. (2011). As mulheres aprisionadas e os reflexos familiares decorrentes do cárcere. Dissertação de Mestrado, Programa de Pós-graduação em Direito, Universidade Federal de Santa Catarina, Florianópolis/SC.

Moreira, V. S. (2012). Impactos do envolvimento de mulheres presidiárias com o fenômeno das drogas. Dissertação de Mestrado, Programa de Pós-graduação em Enfermagem, Universidade Federal da Bahia, Salvador/BA.

Negretti, N. (2015). Madá e Lena entrecruzadas, dois dramas em trama: entre percursos numa tragédia social e uma constituição possível. Dissertação de Mestrado, Programa de Pós-graduação em Ciências Sociais, Pontifícia Universidade Católica de São Paulo, São Paulo/SP.

Oliveira, A. A. (2012). Experiência religiosa no cárcere: o caso do Centro de Reeducação Feminino Maria Júlia Maranhão em João Pessoa - PB. Dissertação de Mestrado, Programa de Pós-graduação em Ciências da Religião, Universidade Federal da Paraíba, João Pessoa/PB.

ONU. (2017). Draft report of the Working Group on the Universal Periodic Review Brazil. Genebra. Recuperado de http://acnudh.org/wp-content/uploads/2017/05/A_HRC_WG.6_27_L.9_ Brazil.pdf

Padovani, N. C. (2010). "Perpétuas espirais": falas do poder e do prazer sexual em trinta anos (19772009) na história da penitenciária feminina da capital. Dissertação de Mestrado, Programa de Pós-graduação em Sociologia, Universidade Estadual de Campinas, SP.

Padovani, N. C. (2015). Sobre casos e casamentos: afetos e "amores" através de penintenciárias femininas São Paulo e Barcelona. Tese de Doutorado, Programa de Pós-graduação em Antropologia Social, Universidade Estadual de Campinas, SP.

Pereira, É. L. (2016). Famílias de mulheres presas, promoção da saúde e acesso às políticas sociais no Distrito Federal, Brasil. Ciência e Saúde Coletiva, 21(7), 2123-2134. https://doi. org/10.1590/1413-81232015217.16792015

Picoli, R. P., Santos, J. P. S., Arazawa, C. Y., Medeiros, I. C. P., Leite, M. F., Furtado, N. et al. (2014). Gestação e puerpério no cárcere: estudo descritivo da atenção à saúde. Revista Baiana de Saúde Pública, 38(1), 67-82.

Sá, P. P. (2013). Ma-estar de arquivo. Tese de Doutorado, Programa de Pós-graduação em Direito, Universidade Federal do Paraná, Curitiba/PR.

Santana, V. R. (2013). “Aceitar Jesus, porque satanás atenta...”: as conversões neopetencostais no presídio feminino de sergipe. Dissertação de Mestrado, Programa de Pós-graduação em Sociologia, Universidade Federal do Sergipe, São Cristovão/SE.

Santos, C. H. (2013). A casa dos homens: passos de uma mulher entre as masculinidades na prisão. Tese de Doutorado, Programa de Pós-graduação em Psicologia, Universidade Estadual Paulista, São Paulo/SP.

Silva, H. M. M. (2014). Perfil sociodemográfico, estilo de vida, condições de saúde e transtorno mental comum de trabalhadores de uma penitenciária feminina do Estado de São Paulo. Dissertação de Mestrado, Programa de Pós-graduação em Saúde Coletiva, Política e Gestão em Saúde, Universidade Estadual de Campinas, SP.

Soares, G. P., Félix-Silva, A. V., \& Figueiró, M. E. S. da S. (2014). Teatro-menor: cartografia em arte e experimentação de mulheres em situação de cárcere. Psicologia छ Sociedade, 26(n.spe), 89-99. https://doi.org/10.1590/So102-71822014000500010 


\section{JÚLIA SURSIS NOBRE FERRO BUCHER-MALUSCHKE \\ https://orcid.org/0000-0002-9194-8993}

Doutora em Ciências Familiares e Sexológicas (Universidade Católica de Louvain).

Endereço: SEPN 707/907 - Campus Universitário, St. de Grandes Áreas Norte - Asa Norte, Brasília/DF, 70790-075, Brasil.

E-mail: psibucher@gmail.com

JONAS CARVALHO E SILVA

http://orcid.org/0000-0002-0893-0283

Doutor em Psicologia Clínica e Cultura (Universidade de Brasília).

E-mail: carvalho707@gmail.com

\section{ISABELA BRITO DOS SANTOS DE SOUZA}

https://orcid.org/0000-0001-9119-1903

Psicóloga (Universidade Católica de Brasília).

E-mail: isabelabritoucb@gmail.com

\begin{tabular}{|c|c|}
\hline Histórico & $\begin{array}{l}\text { Submissão: 09/01/2019 } \\
\text { Revisão: 14/3/2019 } \\
\text { Aceite: 20/8/2019 }\end{array}$ \\
\hline Contribuição & $\begin{array}{l}\text { Concepção: J.S.N.F.B.M.; J.C.S; I.B.S.S. } \\
\text { Coleta de dados: J.S.N.F.B.M.; J.C.S; I.B.S.S. } \\
\text { Análise de dados: J.S.N.F.B.M.; J.C.S; I.B.S.S. } \\
\text { Elaboração do manuscrito: J.S.N.F.B.M.; J.C.S; I.B.S.S. } \\
\text { Crítico de conteúdo intelectual importante: J.S.N.F.B.M.; } \\
\text { J.C.S; I.B.S.S. } \\
\text { Aprovação final do manuscrito: J.S.N.F.B.M.; J.C.S; I.B.S.S. }\end{array}$ \\
\hline Financiamento & $\begin{array}{l}\text { A pesquisa teve o financiamento da Fundação de Apoio à } \\
\text { Pesquisa do Distrito Federal. } \\
\text { J.S.N.F.B.M. é bolsista de produtividade em Pesquisa do } \\
\text { CNPq - Nível C1. } \\
\text { J.C.S é bolsista da Chanceler Federal Alemã pela Fundação } \\
\text { Alexander von Humboldt. }\end{array}$ \\
\hline $\begin{array}{l}\text { Consentimento de } \\
\text { uso de imagem }\end{array}$ & Não se aplica. \\
\hline
\end{tabular}

